\title{
DEVELOPMENT OF INNOVATIVE METHOD OF STEEL SURFACE HARDENING BY A COMBINED CHEMICAL-THERMAL TREATMENT
}

\author{
Kateryna Kostyk \\ Department of Foundry \\ National Technical University "Kharkiv Polytechnic Institute» \\ 21 Bagaliya str., Kharkiv, Ukraine, 61002 \\ eklitus@yandex.ru
}

\begin{abstract}
The aim of the article is a hardening of the surface steel layers due to the combination treatment. Samples of steel $38 \mathrm{Cr} 2 \mathrm{MoAl}$ were hardened by complex chemical and thermal treatment such as carburizing and subsequent boriding. It was established that surface double-layer hardening for steel $38 \mathrm{Cr} 2 \mathrm{MoAl}$ with sequential saturation with atomic carbon (during carburizing) and atomic boron (during furnace boriding) at different temperatures allowed to form a boride layer with transition zone.

The obtaining transition zone can improve operational properties of machine parts and tools by micro-friability reduction of diffusion layer. An optimal mode of complex chemical-thermal treatment (CTT) was obtained for the regime, which includes carburizing at $950{ }^{\circ} \mathrm{C}$ for 2 hours, boriding at $950{ }^{\circ} \mathrm{C}$ for 2 hours, which allows to get the best value for the surface hardness of $22 \mathrm{GPa}$ with a maximum overall diffusion layer $1.4 \mathrm{~mm}$. Due to the technology of combined treatment we can significantly reduce treatment time compared to traditional hardening means and significantly improve product performance properties due to the transition zone between the borides and the matrix of machine elements. The technology can be used in enterprises where there is any hardening furnace without additional installation or conversion of equipment.
\end{abstract}

Keywords: combined treatment; carburizing and subsequent boriding; chemical-thermal treatment; steel surface hardening; improvement of operational properties of machine elements.

\section{Introduction}

Efficiency of borided layers is largely determined by the operational conditions of hardened machine elements or tools [1]. However, common to all cases is a tendency of materials to accumulate damage on the surface and volume of machine elements, as well as resistance to the external environment.

If for the plastic material damage accumulation by friction occurs within a few years, because it is accompanied by plastic deformation of the surface layers and their subsequent defamation and loss of plasticity, then for friable materials this process occurs within weeks of operation, and friable fracture of surface layers can occur even in the initial operation point of machine elements [2].

The resistance of the material surface to the external environment during operation depends on the electrochemical heterogeneity, the presence of dense secondary protective structures generated by friction and the type of external environment. The prevailing value of a factor is determined by the value and difference of electrode phase potentials and structural components of the alloy on its surface, type of external environment and friction conditions.

From the standpoint of corrosion interaction between borided layers and external environment, the most appropriate is a single-phase structure. According to operational requirements that apply to machine element, multiphase structure with close values of electrode potentials is allowed, i. e. with minimal electrochemical heterogeneity. Also in multiphase structure by having a soft layer component on friction surfaces, screening secondary structures that reduce the electrochemical heterogeneity of the surface are easy formed [2].

From the standpoint of borided machine elements wear during extreme abrasive and boundary sliding friction, the best properties have machine elements with the compact structure of boride phases. For the conditions of sliding and rolling friction with alternating load in the presence of lubricant properties, the best properties have the layers with multiphase structures containing hard and soft components and have a certain level of hardness, even 1100-1400 HV [3]. 
Thus, the longevity basis for friction assembly machine elements with coating identifies some plasticity margin of the surface layers, the optimal level of which is in accordance with the material properties and operation conditions.

\section{Review of the problem of friability reduction of borided layers}

In the world there are several well-known scientific schools, studying this process: in Germany under the direction of Kunst H., Schaaber O., Graf von Matuschka A., Vetters H., Maug R.; in England - Bell T.; in France - Andrieux J. L, Gantois M., Goeuriot M.; in Japan - Kavakami Mamoru, Muta Akinori, Takamoto Nabudziro; in the USA - Cook N. C. and other. Leading firms in the field of chemical and thermal treatment of metals and alloys are implemented and engaged in this process: Degussa (Germany), Leybold Durferrit (Germany), Sandvik AB (Japan), Stahlwerke Röchling-Burbach (Germany) and other. Also, there are the following schools: Moscow (Minkevych A., Lakhtin Yu., Gorbunov N.), Belarusian (Lyakhovich L., Voroshnin L., Belsky E., Krukovych M.), Kiev (Samsonov R., Epik A.) Ural (Ilyuschenko N.), Voronezh (Korotkov S., Permiakov V., Loskutov V.) and other. During the study of boriding process and solving a problem of friability of borided layer that was started from 1970-1980, considerable material for different boriding processes and its features was accumulated [4-7].

Classification of processes were carried out in the structure of obtained layers, the technology of processes that are intertwined with the classification by the formation mechanisms of saturating atoms that was not allowed to disclose all relationships. These classifications were summarized the results and helped to better understand the process of treatment and find ways of sustainable use.

The current status of boriding process can be represented as a classification that considers a process according to four criteria [8]:

- generation mechanism of saturating boron atoms;

- technological features, including all known projects;

- phase composition and structure;

- process temperature and its purpose.

Analysis of baseline saturating media showed the presence of boron in two states: atomic and ionic. In this, medium may be in the four states of matter in nature (gas, solid, liquid and plasma).

The friability of boride layer is determined by many factors, including the ratio of FeB and $\mathrm{Fe}_{2} \mathrm{~B}$ phases in the layer, morphology of the borides, stress condition and other. It also depends on continuity of boride layer on the strengthen surface. Optimal saturating medium ensures continuity of saturating element supply to processed surface. Surface layer of uneven thickness or fragmented structure of some borided zones or layer of separated needles of borides is formed in the case of continuity violation [9].

General interconnected ways for friability reduction of boride phases is optimal microalloying and creation of a favorable stress state. These ways are implemented by following technological measures [10]:

- microalloying of saturating medium layer;

- lowering the content of friable FeB phase in the layer;

- pretreatment of surfaces;

- establishing optimum temperature and time conditions;

- the rate of cooling after saturation;

- additional treatment of obtained borided layers;

- final thermal and mechanical treatment.

Friability reduction of boride phases is provided by control of layer density level, which significantly affects its stress state. This is achieved, for example, at high-temperature boriding that causes generation of more generation centers of $\mathrm{Fe}_{2} \mathrm{~B}$ phase at the initial process stage [11-14].

Efficiency of borided layers is largely determined by the operation conditions of hardened machine elements or tools. However, common to all cases is a tendency to accumulate material damage on the surface and volume of machine elements, as well as resistance to environmental influences [13-16]. 
From the position of anticorrosive interaction of boride layers with the environment, the most appropriate is a single-phase structure [15-19].

To improve efficiency of boride layers it is necessary an optimal combination of their thickness and material of the matrix, also depending on the cooling rate after boriding or the type of heat treatment matrix is sometimes observed spontaneous cleavage of separate layer zones, due to high residual stresses. At the same time there is a maximum thickness of borided layers for a particular type of steel and its heat treatment when they have a strong bond with the matrix and have some plasticity margin [20].

\section{Materials and Methods}

Table 1

CTT modes

\begin{tabular}{cll}
\hline № & Carburizing & Boriding \\
\hline 1 & $800^{\circ} \mathrm{C}, 2$ hours & $800{ }^{\circ} \mathrm{C}, 2$ hours \\
2 & $850{ }^{\circ} \mathrm{C}, 2$ hours & $850{ }^{\circ} \mathrm{C}, 2$ hours \\
3 & $900^{\circ} \mathrm{C}, 2$ hours & $900{ }^{\circ} \mathrm{C}, 2$ hours \\
4 & $950{ }^{\circ} \mathrm{C}, 2$ hours & $950{ }^{\circ} \mathrm{C}, 2$ hours
\end{tabular}

The microstructure and thickness of diffusion layers were investigated by optical microscopy at MIM-8 microscope (Russia) using a technique at different magnifications [12, 22].

The distance of microhardness changes from surface values to core hardness was take for thickness of borated layer, which contain borides and transition zone.

Microhardness of the samples was determined using device PMT-3 (Russia) with a load of $50,100 \mathrm{~g}$ and endurance $7-15$ seconds in accordance with technique [12, 22].

\section{Experimental investigation of sequential saturation ways of steel surface layers with car- bon and boron}

\section{1. Steel carburization}

Carburizer preparation is reduced to charcoal crushing and its sifting through sieves; fragmented coal $(3.5-10 \mathrm{~mm})$ is watered with an aqueous solution of carbonate salts (solution temperature $50-80{ }^{\circ} \mathrm{C}$ ), mixed thoroughly and dried at $100-150{ }^{\circ} \mathrm{C}$.

Carburized samples after pre-treatment are placed in welded steel containers with a diameter of $80 \mathrm{~mm}$ and a height of $180 \mathrm{~mm}$. Carburizer layer with a thickness of 20-30 $\mathrm{mm}$ is filled and tamped, when packing items to the bottom of the container. The first row of samples is placed on the carburizer, maintaining a distance between the samples and to the side walls of the container of 10-15 mm. Then, the carburizer layer of 10-15 mm thickness is filled and tamped. The second layer of samples is placed on it. The last (top) row of samples is covered by carburizer layer with a thickness of 35-40 mm in order to compensate its possible shrinkage. 6 layers of rectangular samples $8 \times 8 \times 10 \mathrm{~mm}$ were placed in a container. Samples occupy $15-20 \%$ of the container volume. The container is covered with a lid, coated with refractory clay or a mixture of clay and river sand. Then the container is placed in the oven. Heat was conducted to temperature: $800{ }^{\circ} \mathrm{C}, 850{ }^{\circ} \mathrm{C}, 900{ }^{\circ} \mathrm{C}$, $950{ }^{\circ} \mathrm{C}$ and kept for 2 hours. After carburization container was cooled in air to $400-500{ }^{\circ} \mathrm{C}$ and then opened [13].

\section{2. Steel boriding}

The surface of the samples was purified from traces of scale, rust, grease and other contaminants before boriding. Minor contamination was removed by $96 \%$ alcohol. Boriding in the powder mixture is carried out based on boron-contained substances. 
The paste layer in the basis of boron-contained substances was applied [21], namely $80 \%$ of amorphous boron adding activators $10 \% \mathrm{LiF}$ and $10 \% \mathrm{NaF}$, components were mixed dry, then binding components were added ( $96 \%$ alcohol and solution of BF-2 glue in acetone) two or three times with a drying at $140{ }^{\circ} \mathrm{C}$ for $30-40$ minutes until paste drying. Further the samples that interspersed by magnesium polyboride were contained in the crucible. They were putted in a chamber oven for 120 minutes at $800^{\circ} \mathrm{C}, 850^{\circ} \mathrm{C}, 900^{\circ} \mathrm{C}, 950{ }^{\circ} \mathrm{C}$. Samples after boriding were subjected to heat treatment, hardening and tempering. Hardening was performed at temperatures of boriding in the oil. Tempering was carried out in a chamber furnace at $200{ }^{\circ} \mathrm{C}$ for 1.5 hours with subsequent cooling in still air $[21,22]$.

\section{Results}

Operating properties of boride layers are defined by the set of boride and sublayer properties. Sublayer has a largest part at heat treatment of boriding machine elements that creates solid substrate to the layer of borides and prevents its bursting, as well as the formation of the stress condition of machine elements. In this case, it is necessary to adjust the heating temperature in quenching taking into account changed composition of sublayer to obtain optimal complex of properties of machine elements. Some importance for the processes of deterioration has sublayer that was hardened by thermal or chemical-thermal treatment. Due to a high hardness and presence of carbides it provides further increased durability of machine element compared to the core durability after wear of boride layer.

Formation of the sublayer, which is the transition zone from borides to the structure of the base metal, is both in the saturation process and cooling and subsequent thermal treatment (Fig. 1). The structure of the transition zone essentially depends on the composition of alloying elements in steel. For example, boriding of medium-carbon steels with more than $5 \%$ of chromium and more than $1 \%$ of aluminum leads to the formation $\alpha$-solid solution of these elements in the sublayer. These elements have reduced hardness and cause cracking and chipping of boride layer.

Steel alloying level determines the nature of carbon redistribution and structure of sublayer. This is reflected in the reduced thickness of the sublayer and a lowering of carbon concentration in it. Carbide-forming elements (chromium and molybdenum) significantly impede diffusion of boron atoms in the sublayer and, thus, prevent the growth of grain in it, which positively affects the mechanical properties of the steel.

The hardness of the sublayer depends on the steel grade and speed of further cooling or heat treatment. In the heat treatment of high-alloy steels, sublayer is additionally hardened by a secondary crystallization process, $i$. e. the selection of borides and carbides of various shapes from solid solutions.

The main characteristic of saturating medium at CTT is its activity and potential. They are characterized by the concentration of diffusing element on the metal surface at equilibrium with the atmosphere. This equally applies to liquids, solids and gases used in the CTT. The activity of the atmosphere depends on its composition, temperature and pressure in the working space of the furnace.

It can be concluded that the temperature is directly affects the depth of the diffusion layer of steel under complex chemical and thermal treatment.

The depth dependence of diffusion layers for $38 \mathrm{Cr} 2 \mathrm{MoAl}$ steel from the temperature after a comprehensive CTT is given in Table 2.

\section{Table 2}

The depth dependence of diffusion layers for $38 \mathrm{Cr} 2 \mathrm{MoAl}$ steel after each CTT and overall treatment from the temperature

\begin{tabular}{cccc}
\hline $\mathbf{8 0 0}$ & $\mathbf{8 5 0}$ & $\mathbf{9 0 0}$ & $\mathbf{9 5 0}$ \\
\hline $25-30$ & $35-40$ & 55 & 60 \\
$40-50$ & 140 & 660 & 1300 \\
$65-70$ & 180 & 715 & 1360
\end{tabular}



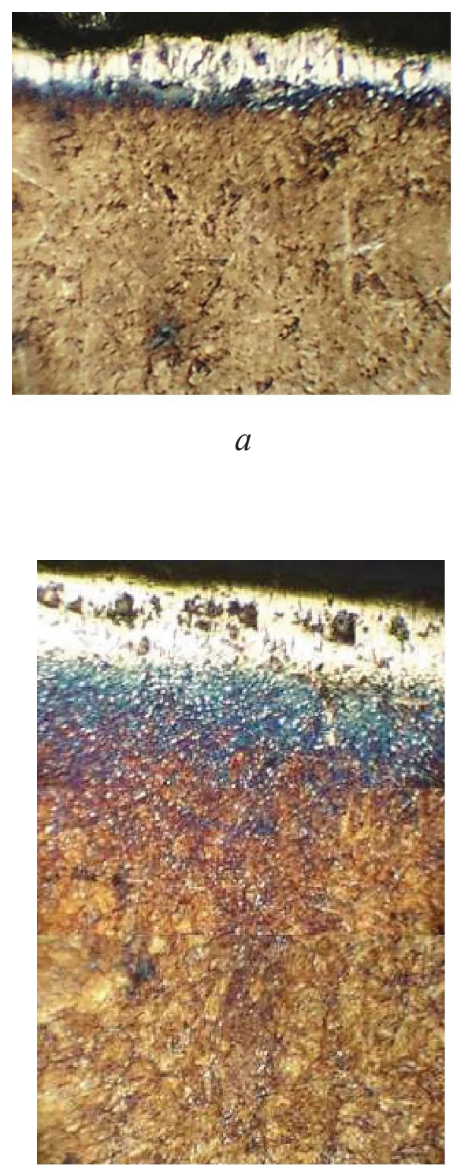

$c$

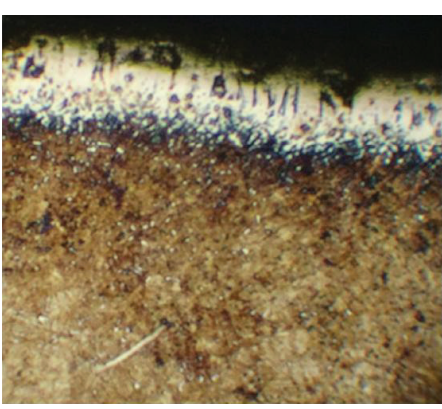

$b$

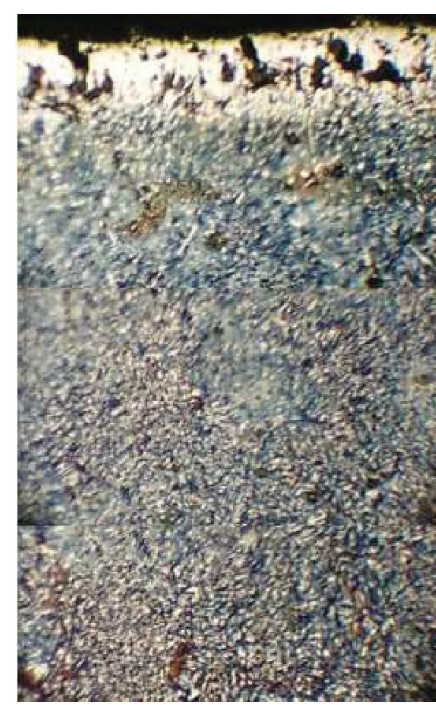

$d$

Fig. 1. 38Cr2MoAl steel microstructures after comprehensive CTT in the modes described in Table 1 at 300 times magnification; $a$-mode № $1 ; b$ - mode №2; $c$-mode № $3 ; d$ - mode № 4

A characteristic feature of boride layers is a high hardness. Microhardness of FeB boride is $22 \mathrm{GPa}$ and $\mathrm{Fe}_{2} \mathrm{~B}$ boride - $18 \mathrm{GPa}$. Increase of carbon content in the steel reduces the hardness of $\mathrm{FeB}$ boride and slightly affects $\mathrm{Fe}_{2} \mathrm{~B}$ hardness. Increase of boriding temperature of carbon steel decreases $\mathrm{FeB}$ hardness and slightly increases $\mathrm{Fe}_{2} \mathrm{~B}$ hardness. Saturation time is practically not affected on hardness of boride phases. High microhardness of borided layer does not yield microhardness of hardened medium-carbon steel. This allows using boriding to improve the durability of products $[12,21,22]$.

When CTT temperature is increased (Table 2), thickness of borated layer is increased and reaches $1360 \mu \mathrm{m}$. The best mode for boriding is temperature $950{ }^{\circ} \mathrm{C}$ at which high surface hardness, wear resistance and corrosion resistance are provided.

\section{Discussion}

Technology of combined hardening allows significantly reduce treatment time compared to traditional hardening means and significantly improve product performance properties due to the transition zone between borides and the matrix of machine elements.

The technology can be used in enterprises where there is any hardening furnace without additional installation or conversion of equipment.

The fact of sublayer formation with increased carbon content can be considered as acceptable because it provides solid substrate to the layer of borides after hardening. In general, this creates an increased hardened zone, a smooth hardness difference from the layer to the core and high mechanical properties of borided machine elements. 
The current technological variant of combined hardening in the powder mixtures can be recommended for hardening of products with a complex shape, especially if after boriding they are not heat treated, because grooving and deformation for this boriding method are minimal.

Also, the technology is appropriate when it is necessary for hardening of large-scale products or combination of boriding with heat treatment.

Further researches will be aimed at finding other technologies to friability reduction of borided layers, namely the use of combined technologies for chemical and thermal treatment using sequential processes of nitrogen, carbon and boron saturation.

\section{Conclusions}

1. Surface double-layer hardening of 38X2MЮA steel with sequential saturation with atomic carbon (during cementation) and atomic boron (during furnace boriding) at different temperatures allowed to form a boride layer with transition zone.

2. Obtained transition zone can increase operational properties of machine elements and tools by microfriability reduction of diffusion layer.

3. An optimal mode of complex CTT was selected. It is a mode 4 , which includes carburizing at $950{ }^{\circ} \mathrm{C}$ for 2 hours, boriding at $950{ }^{\circ} \mathrm{C}$ for 2 hours to obtain the maximal surface hardness of $22 \mathrm{GPa}$ with a maximal overall diffusion layer of $1.4 \mathrm{~mm}$.

\section{References}

[1] Kostik, V. O., Sapuckaja, O. V., Kostik, E. A. (2005). Formirovanie mikrostruktury borirovannogo sloja na poverhnosti uglerodistoj konstrukcionnoj i instrumental'noj staljah iz obmazok pri pechnom nagreve. Eastern-European Journal of Enterprise Technologies, 5 (1 (17)), 63-68.

[2] Kostyk, K. O. (2015). Zmicznennya poverhni instrumentu zi stali 38Cr2MoAl kompleksnoyu himiko-termichnoyu obrobkoyu. Visnyk Nacionalnogo tehnichnogo universytetu «KhPI». Seriya: Novi rishennya u suchasnyh tehnologiyah, 1 (39), 26-33.

[3] Padhy, M. K., Saini, R. P. (2008). A review on silt erosion in hydro turbines. Renewable and Sustainable Energy Reviews, 12 (7), 1974-1987. doi: 10.1016/j.rser.2007.01.025

[4] Elias-Espinosa, M., Ortiz-Domínguez, M., Keddam, M., Gómez-Vargas, O. A., ArenasFlores, A., Barrientos-Hernández, F. R., Sinclair, D. C. (2015). Boriding kinetics and mechanical behaviour of AISI O1 steel. Surface Engineering, 31 (8), 588-597. doi: 10.1179/1743294415y.0000000065

[5] Piasecki, A., Kulka, M., Kotkowiak, M. (2016). Wear resistance improvement of 100CrMnSi6-4 bearing steel by laser boriding using CaF2 self-lubricating addition. Tribology International, 97, 173-191. doi: 10.1016/j.triboint.2016.01.028

[6] Erdogan, M., Gunes, I. (2015). Corrosion Behavior and Microstructure of Borided Tool Steel. Matéria (Rio de Janeiro), 20 (2), 523-529. doi: 10.1590/s1517-707620150002.0052

[7] Domínguez, M. O., Silva, J. Z., Keddam, M., Mejía, O. D., Espinosa, M. E. (2015). Diffusion model and characterisation of Fe2B layers on AISI 1018 steel. International Journal of Surface Science and Engineering, 9 (4), 281-297. doi: 10.1504/ijsurfse.2015.070808

[8] Kulka, M., Makuch, N., Pertek, A. (2013). Microstructure and properties of laser-borided 41Cr4 steel. Optics \& Laser Technology, 45, 308-318. doi: 10.1016/j.optlastec.2012.06.030

[9] Altinsoy, I., Efe, F. G. C., Ipek, M., Ozbek, I., Zeytin, S., Bindal, C. (2013). An investigation on borided AISI 1020 steel. AIP Conf. Proc. doi: 10.1063/1.4849225

[10] Gunes, I., Taktak, I., Bindal, C., Yalcin, Y., Ulker, S., Kayali, Y. (2013). Investigation of diffusion kinetics of plasma paste borided AISI 8620 steel using a mixture of B 2 O 3 paste and B $4 \mathrm{C} / \mathrm{SiC}$. Sadhana, 38 (3), 513-526. doi: 10.1007/s12046-013-0136-2

[11] Idan, A. F. I., Akimov, O., Golovko, L., Goncharuk, O., Kostyk, K. (2016). The study of the influence of laser hardening conditions on ithe change $\mathrm{n}$ properties of steels. Eastern-European Journal of Enterprise Technologies, 2 (5 (80)), 69-73. doi: 10.15587/1729-4061.2016.65455

[12] Kostyk, K. (2015). Development of the high-speed boriding technology of alloy steel. EasternEuropean Journal of Enterprise Technologies, 6 (11 (78)), 8-15. doi: 10.15587/1729-4061.2015.55015

[13] Czerwinski, F. (2012). Thermochemical Treatment of Metals. Heat Treatment - Conventional and Novel Applications. doi: 10.5772/51566 
[14] Kulka, M., Makuch, N., Pertek, A., Piasecki, A. (2012). Microstructure and properties of borocarburized and laser-modified 17CrNi6-6 steel. Optics \& Laser Technology, 44 (4), 872-881. doi: 10.1016/ j.optlastec.2011.11.016

[15] Aghaie-Khafri, M., Mohamadpour Nazar Abady, M. (2012). A Study of Chromo-Boronizing on DIN 1.2714 Steel by Duplex Surface Treatment. JOM, 64 (6), 694-701. doi: 10.1007/s11837-012-0337-x

[16] Kartal, G., Kahvecioglu, O., Timur, S. (2006). Investigating the morphology and corrosion behavior of electrochemically borided steel. Surface and Coatings Technology, 200 (11), 3590-3593. doi: 10.1016/j.surfcoat.2005.02.210

[17] Veropakha, N. V., Veropakha, D. N., Skorykov, A. V. (2006). Effect of liquid boriding on wear and corrosion resistance of long products. News of universities. Actual problems of mechanical engineering, 20-21.

[18] Alyev, A. A., Bulhakov, V. P., Prykhodko, B. S. (2005). Diffusion boronizing of steel and surface roughness. Vestnik of Astrakhan state technical University, 2, 91-94.

[19] Stergioudis, G. (2006). Formation of boride layers on steel substrates. Crystal Research and Technology, 41 (10), 1002-1004. doi: 10.1002/crat.200610711

[20] Sen, S., Sen, U., Bindal, C. (2005). An approach to kinetic study of borided steels. Surface and Coatings Technology, 191 (2-3), 274-285. doi: 10.1016/j.surfcoat.2004.03.040

[21] Pavliuchenko, O. O., Kostyk, V. O., Kostyk, K. O. (2008). Patent of Ukraine, 33654; MPK 8C238/00. Composition for boriding steel product Application № u200800226. Declarated: 04.01.08; published: 10.07.08, bul. 13 .

[22] Kostyk, K. O. (2013). Zmicznennya pres-form lyttya pid tyskom po nanotehnologiyi. Mashynobuduvannya, $12,113-118$. 